\title{
Secretory Granule
}

National Cancer Institute

\section{Source}

National Cancer Institute. Secretory Granule. NCI Thesaurus. Code C26062.

Usually a protein, it is produced in the granular endoplasmic reticulum and the Golgi complex. Morphologically, it is defined as a membrane-bound particle. 